\title{
Resultados de la evaluación del modelo educativo para la formación por competencias laborales en los alumnos de la División de Ingenierías de la Universidad de Guanajuato
}

Results of the Evaluation of the Educational Model for the Training by Labor Competences in the Students of the Engineering Division of the University of Guanajuato

\begin{abstract}
Resultados da avaliação do modelo educacional para a formação por competências laborais nos alunos da Divisão de Engenharia da Universidade de

Guanajuato
\end{abstract}

Víctor Guillermo Flores Rodríguez Universidad de Guanajuato. División de Ingenierías, México victor@ugto.mx https://orcid.org/0000-0001-8912-519X

Nélida Bethel Alcalá Cortés Universidad de Guanajuato. División de Ingenierías, México nalcala@ugto.mx https://orcid.org/0000-0001-9667-4381

\section{Resumen}

Este artículo presenta los resultados de una investigación llevada a cabo en la División de Ingenierías de la Universidad de Guanajuato (UG), Campus Guanajuato, y cuyo objetivo general fue evaluar la implementación del modelo educativo para la formación por competencias laborales en los alumnos, así como determinar el impacto que tuvo la actualización curricular de los programas educativos. Esto con la finalidad de definir las acciones que se deben realizar para que los docentes cuenten con las competencias genéricas especificadas en el Modelo Educativo de la UG. 


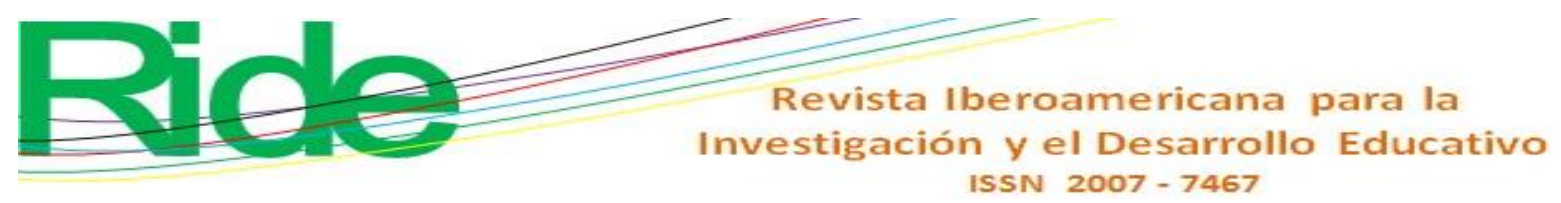

Se seleccionó una muestra de 1460 alumnos de un total de 1722 estudiantes que estuvieron inscritos en los diferentes programas educativos de la división ya mencionada en el semestre enerojunio de 2015. Esta muestra y las técnicas e instrumentos utilizados para la recolección de la información, al igual que el método de análisis factorial, facilitaron la consecución de las metas planteadas.

Entre las conclusiones se resalta la importancia de diseñar, aplicar y evaluar programas de intervención tanto para estudiantes como para profesores capaces de modificar, en cada caso, los enfoques de enseñanza-aprendizaje, así como de contar con una herramienta educativa que permita desarrollar en el alumno el afán de búsqueda y de creatividad para alcanzar una mejor comprensión de los fenómenos y facilitar el aprendizaje y la práctica misma de los conocimientos.

Palabras clave: competencias del egresado, modelo educativo, práctica docente.

\section{Abstract}

The present article shows the results of a research carried out in the Engineering Division of the Guanajuato University and whose main purpose was to evaluate the implementation of the Educational Model focused in training students for labor competencies, as well as to determine the impact that had the curricular update of the educational programs. This with the purpose of defining the actions that must be carried out so that the teachers have the generic competences required by the University of Guanajuato.

A sample of 1460 from a total of 1722 undergraduate students was selected from the division above mentioned. This sample the techniques and instruments used to collect the information, as well as the method of analysis factor, allowed the achievement of the goals set.

Among the conclusions it is highlighted the importance of designing, applying and evaluating intervention programs for both students and teachers capable of modifying, in each case, the teaching-learning approaches, as well as having an educational tool that allows to develop in the student the desire for search and creativity to achieve a better understanding of the phenomena and facilitate not only learning, but the practice of knowledge.

Keywords: graduates competencies, educational model, teaching practice. 


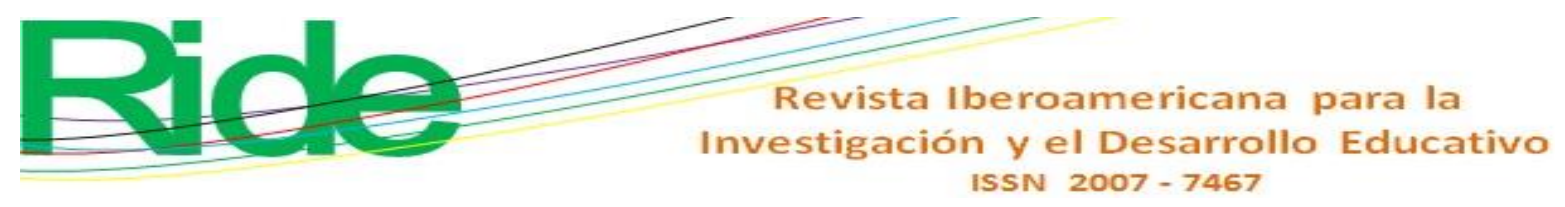

\section{Resumo}

Este artigo apresenta os resultados de uma pesquisa realizada na Divisão de Engenharia da Universidade de Guanajuato (UG), Campus Guanajuato, e cujo objetivo geral foi avaliar a implementação do modelo educacional de formação por habilidades profissionais em estudantes, bem como como determinar o impacto da atualização curricular de programas educacionais. Isso com o objetivo de definir as ações que devem ser realizadas para que os professores tenham as competências genéricas especificadas no Modelo Educacional da UG.

Uma amostra de 1460 alunos foi selecionada de um total de 1722 alunos que estavam matriculados nos diferentes programas educacionais da divisão já mencionados no semestre de janeiro a junho de 2015. Esta amostra e as técnicas e instrumentos usados para coletar as informações, Como o método de análise fatorial, eles facilitaram o alcance das metas estabelecidas.

As conclusões destacam a importância de projetar, aplicar e avaliar programas de intervenção para alunos e professores capazes de modificar, em cada caso, as abordagens de ensino-aprendizagem, bem como ter uma ferramenta educacional que permita desenvolver no aluno o desejo de busca e criatividade para alcançar uma melhor compreensão dos fenômenos e facilitar o aprendizado e a prática do conhecimento.

Palavras-chave: competências do graduado, modelo educacional, prática docente.

Fecha Recepción: Mayo 2018

Fecha Aceptación: Noviembre 2018

\section{Introducción}

Planear un escenario de aprendizaje implica considerar la mayor cantidad posible de variables orientadas al logro y construcción de las competencias integrales de los alumnos: académicas, disciplinares, transversales, actitudinales y de acción, considerando una labor creativa e innovadora desde la práctica del docente para lograr tal propósito.

Los proyectos son una opción de vinculación de todos los contenidos curriculares y las experiencias trabajadas dentro y fuera del aula para construir competencias educativas que puedan ser aplicadas en la vida cotidiana del estudiante. $\mathrm{Y}$ un proyecto integral es aquel que se realiza 


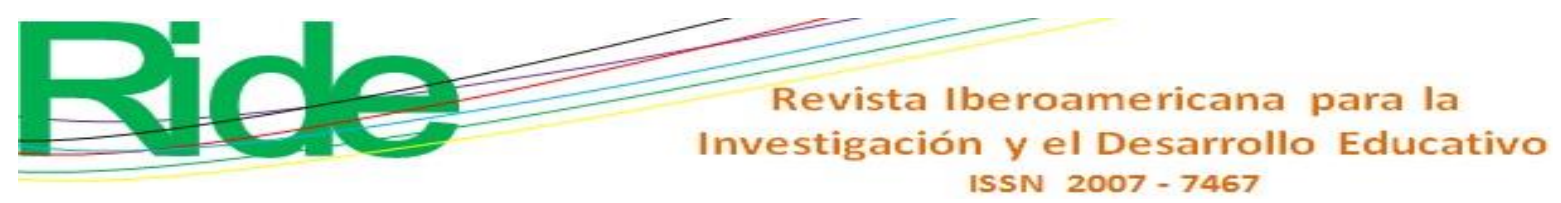

desde un área disciplinar con el fin de hacer conexiones con otras asignaturas y experiencias de aprendizaje para estimular el aprendizaje con sentido en los alumnos. Se fundamenta, por supuesto, en la puesta en práctica de habilidades docentes, creativas y críticas, (U. G., 2018).

Respecto a la innovación educativa, se trata de la posibilidad de recrear situaciones que, de acuerdo con el contexto, sorprendan favorablemente a los participantes. En suma, construir escenarios en los que se exploren diferentes posibilidades estratégicas para el aprendizaje de alumnos y profesores (Universidad de Guanajuato, 2011).

En México, desde 1991, las universidades pertenecientes a la Asociación Nacional de Universidades e Instituciones de Educación Superior (Anuies) convinieron en fomentar una cultura de evaluación como base para obtener mejoras en todos sus procesos educativos. Posteriormente, acordaron los criterios de calidad en el ámbito institucional y, con ese acuerdo fundamental, han trabajado sistemáticamente y obtenido logros concretos y visibles.

La Universidad de Guanajuato (UG) ha mostrado un ritmo constante para alcanzar este propósito en común y se ha colocado en un lugar distintivo dentro del ámbito universitario nacional. Para llegar a este nivel, la UG ha desplegado un ejercicio de planeación participativo extendido a toda la comunidad y, en sus instancias directivas, un esfuerzo de gestión integral que incluye el crecimiento de la matrícula, de sus indicadores de calidad y de su infraestructura. Lo anterior se ha logrado gracias al notable crecimiento académico en prácticamente todas sus áreas, lo que ha permitido duplicar su presupuesto en los últimos seis años, especialmente a través de los fondos extraordinarios de los gobiernos federal y estatal (UG, 2018).

Sin embargo, este próspero ambiente universitario no puede limitar el aprendizaje a asuntos unidisciplinarios, sino que debe fortalecer y propiciar lo necesario para aprender en un ámbito multidisciplinar, y así favorecer el análisis integral de objetos de estudio trascendentales que posibilite a los estudiantes lograr sus competencias genéricas y específicas (Universidad de Deusto/Universidad de Groningen, 2007). Al mismo tiempo, este entorno debe fomentar los valores universitarios expresados en su código de ética (UG, 2018).

El Modelo Educativo de la UG se deriva del Plan de Desarrollo Institucional (Pladi) 20102020, el cual busca atender la preocupación arriba mencionada, y se estructura en tres planos: conceptual, ejecutivo y operativo. Los elementos que lo componen son los siguientes: el estudiante, que es el centro del modelo; el profesor; el aprendizaje y la evaluación; la investigación; la 


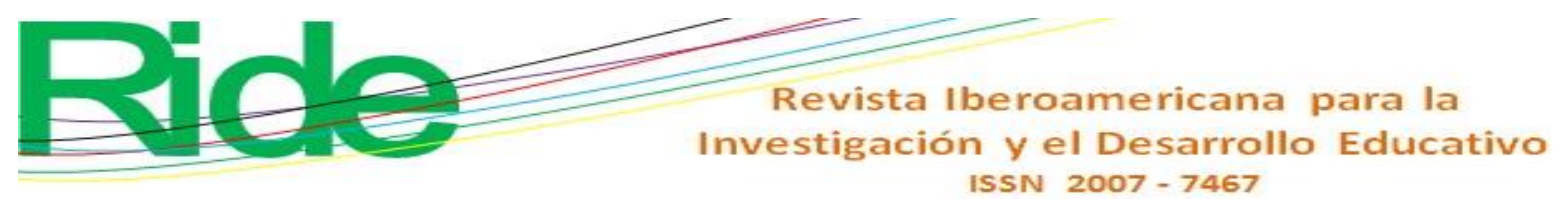

administración; la calidad, certificación e innovación; los procesos de planeación, coordinación y evaluación; la vinculación; la internacionalización, y la infraestructura física y el equipamiento.

Con base en lo dicho hasta aquí surgió la siguiente pregunta de investigación: ¿Cómo se logrará que el estudiante se adecue a esta ideología y con ello contribuir no solamente al desarrollo de sus competencias estudiantiles y profesionales, sino de la sociedad misma? Por lo tanto, el estudio se centró en analizar estos elementos tomando como referencia a los alumnos de licenciatura de la División de Ingenierías del Campus Guanajuato de la UG para establecer cuáles son los medios para llegar a tal fin.

De tal modo que el objetivo general de esta investigación se enfocó en evaluar la implementación del Modelo Educativo para la formación por competencias laborales en los alumnos de la División de Ingenierías del Campus Guanajuato de la UG. Mientras que los objetivos específicos fueron los puestos a continuación: 1) actualizar el currículo de los programas educativos de la División de Ingenierías para que cumplan con el nuevo modelo educativo de la UG y 2) determinar las acciones que se realizarán para que los profesores estén capacitados para cumplir sus labores con base en el Modelo Educativo de la UG y desarrollen sus labores docentes en beneficio de los alumnos con un enfoque de formación por competencias.

\section{Materiales y métodos}

Para realizar el análisis de los datos obtenidos en la aplicación de los instrumentos en la muestra de los alumnos de la División de Ingenierías del Campus Guanajuato, se utilizó el paquete estadístico Statistical Product and Service Solutions (SPSS), versión 22.0. Por el tipo de ítems del instrumento aplicado y las variables estudiadas, para identificar su conocimiento y comprensión del Modelo Educativo de la UG, así como su perspectiva de desarrollo dentro de esta institución, se seleccionó el método estadístico de análisis factorial, ya que es una técnica de reducción de datos ideal para encontrar grupos homogéneos de variables a partir de un conjunto numeroso de variables. Esos grupos homogéneos se forman con las variables que se correlacionan mucho entre sí y procurando, inicialmente, que unos grupos sean independientes de otros (IBM, 2015). 


\section{Descripción y exploración los enfoques de aprendizaje de la muestra de estudio}

Los participantes del estudio se catalogan en cada uno de los enfoques cuando cumplen determinados criterios establecidos (Biggs, 2001). Según el mismo Biggs (2001), el alumnado que posee una puntuación superior a la media en las escalas que componen el enfoque profundo, y a la vez inferior a la media en las escalas del enfoque superficial, adopta un enfoque profundo exclusivamente. Mientras que si, cumpliendo el criterio de ser superior en las escalas del enfoque profundo, se encuentra en la media de las escalas del superficial, el alumnado adopta un enfoque profundo predominante. El alumnado que cumple el caso inverso adopta un enfoque superficial exclusivo y predominante, respectivamente.

La comprobación de los criterios enunciados clasifica la muestra $(n=1233)$ en tres grupos: 1) los alumnos que adoptan un enfoque profundo (89.9\%), 2) alumnos que adoptan un enfoque superficial $(6.5 \%)$ y 3 ) los alumnos que no manifiestan un enfoque determinado $(3.6 \%)$ (ver figura $1)$.

Figura 1. Enfoque de aprendizaje

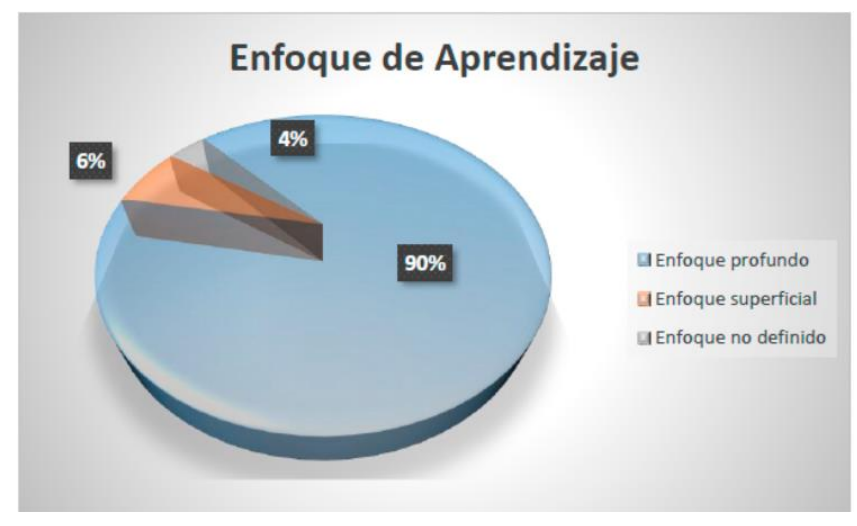

Fuente: Elaboración propia

Las medias de las subescalas del enfoque profundo siempre son más altas que en las subescalas del enfoque superficial (véase tabla 1). 


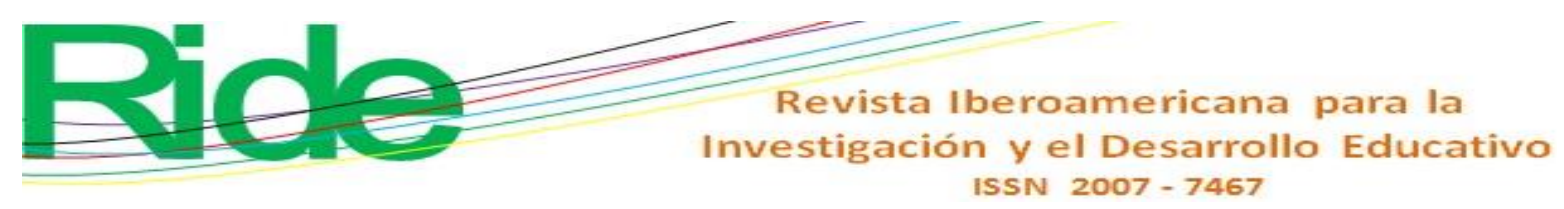

Tabla 1. Enfoques de aprendizaje

\begin{tabular}{|l|c|c|}
\hline \multicolumn{1}{|c|}{ Subescala } & $\chi$ (media) & $\sigma$ (Desviación estándar) \\
\hline Motivos profundos & 4.09 & 2.37 \\
\hline Estrategias profundas & 2.75 & 2.46 \\
\hline Motivos superficiales & -2.48 & 3.25 \\
\hline Estrategias superficiales & -1.12 & 3.34 \\
\hline Enfoque profundo & 6.84 & 4.31 \\
\hline Enfoque superficial & -3.60 & 6.04 \\
\hline
\end{tabular}

Fuente: Elaboración propia

La subescala de motivos profundos $(\chi=4.09 ; \sigma=2.37)$ tiene la media más alta según la clasificación, seguida de la subescala de estrategias profundas $(\chi=2.75 ; \sigma=2.46)$, la subescala de estrategias superficiales $(\chi=-1.12 ; \sigma=3.34$ ) y por último la subescala de motivos superficiales $(\chi$ $=-2.48 ; \sigma=3.25$ ). Por otra parte, la escala de enfoque profundo cuenta con una media $(\chi)$ de 6.84 y una desviación estándar $(\sigma)$ de 4.31 en contraste con el enfoque superficial que cuenta con una media $(\chi)$ de -3.60 y una desviación estándar $(\sigma)$ de 6.04 .

Respecto a las subescalas de motivación de aprendizaje, se determina que, de los alumnos encuestados, $89.9 \%$ tiene una motivación profunda; $6.5 \%$ de los alumnos tienen una motivación superficial, y solamente $3.6 \%$ de los alumnos no tienen motivación alguna.

En lo que respecta a las subescalas de estrategias de aprendizaje, $75.4 \%$ de los alumnos manifiesta tener estrategias profundas; $12.6 \%$ manifiesta contar con estrategias superficiales, y 12 $\%$ de los alumnos no tener ninguna preferencia por alguna estrategia (figura 2). 


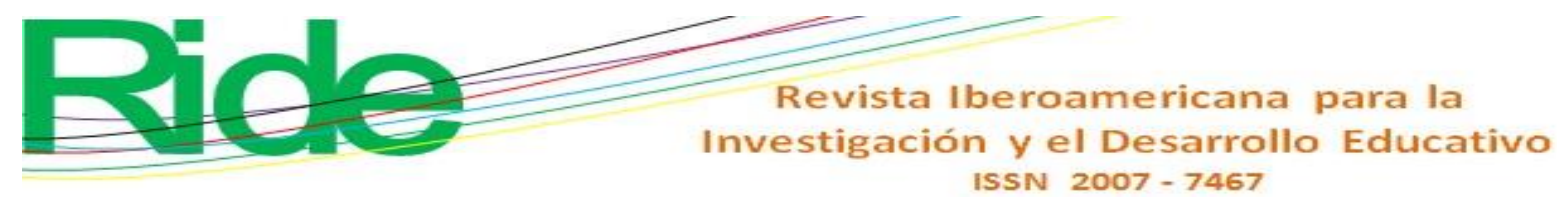

Figura 2. Estrategia de aprendizaje

\section{Estrategia de Aprendizaje}

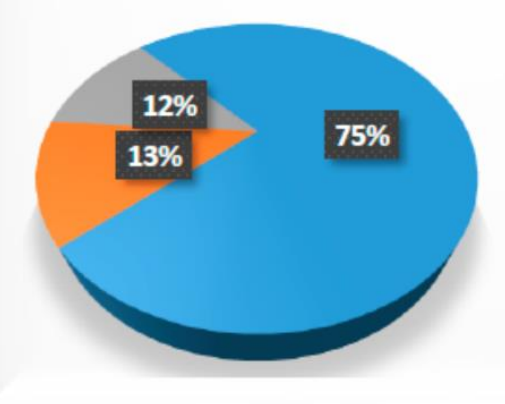

Estrategia profundo

n Estrategiasuperficial

Estrategia no definido

Fuente: Elaboración propia

En suma, se puede observar que los alumnos tienen una relación alta (90 \%) en cuanto a la motivación por el estudio y utilizar estrategias profundas hacia el estudio considerables (75\%). Por lo que se infiere que el aprendizaje para la muestra de estudiantes es un acto emocionalmente grato y de concepción cualitativa, cuya motivación se basa en el interés, la comprensión y la importancia de las materias, y para el cual utilizan estrategias que les permiten planificar de manera adecuada y eficaz las tareas a realizar, gracias a todo ello, una vez más, hacen de esta experiencia una grata y de enriquecimiento personal (Hernández, Martínez, Da Fonseca y Rubio, 2005).

\section{Análisis factorial de datos}

Cuando se lleva a cabo la recopilación de un gran número de variables de forma simultánea, por ejemplo, en un cuestionario de satisfacción laboral, se puede estar interesado en averiguar si las preguntas del cuestionario se agrupan de alguna forma característica. Aplicando un análisis factorial a las respuestas de los sujetos se pueden encontrar grupos de variables con significado común y conseguir de esta manera reducir el número de dimensiones necesarias al momento de explicar las respuestas de los sujetos (IBM, 2015).

El análisis factorial es, por tanto, una técnica de reducción de la dimensionalidad de los datos. Su propósito último consiste en buscar el número mínimo de dimensiones capaces de explicar el máximo de información contenida en los datos. 


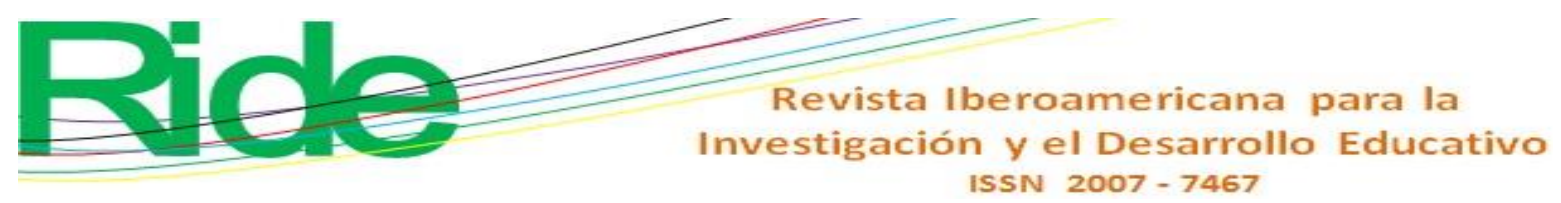

A diferencia de lo que ocurre en otras técnicas, como el análisis de varianza o el de regresión, en el análisis factorial todas las variables del análisis cumplen el mismo papel: todas ellas son independientes en el sentido de que no existe a priori una dependencia conceptual de unas variables sobre otras (IBM, 2015).

En este proceso se realizaron los siguientes análisis ${ }^{1}$ :

- Subescala de motivo profundos. Tomando como base los ítems 1, 5, 9, 13 y 17 del cuestionario aplicado para determinar los motivos profundos; es decir, el interés intrínseco de los alumnos a los hábitos de estudio.

- $\quad$ Subescala de estrategias profundas. Tomando como base los ítems 2, 6, 10, 14 y 18 del cuestionario aplicado para determinar las estrategias profundas; es decir, la búsqueda de la máxima comprensión de los alumnos a los hábitos de estudio.

- $\quad$ Subescala de motivos superficiales. Tomando como base los ítems 3, 7, 11, 15 y 19 del cuestionario aplicado para determinar los motivos superficiales; es decir, el temor al fracaso de los alumnos a los hábitos de estudio.

- $\quad$ Subescala de estrategias superficiales. Tomando como base los ítems 4, 8,12,16 y 20 del cuestionario aplicado para determinar las estrategias superficiales; es decir, el temor al fracaso de los alumnos a los hábitos de estudio.

- $\quad$ Enfoque profundo. Tomando como base los ítems 1, 2, 5, 6, 9, 10, 13, 14, 17 y 18 del cuestionario aplicado para determinar el enfoque profundo; es decir, una combinación entre la subescala de motivación profunda y la estrategia profunda.

- $\quad$ Enfoque superficial. Tomando como base los ítems 3, 4, 7, 8, 11, 12, 15, 16, 19 y 20 del cuestionario aplicado para determinar el enfoque superficial; es decir, una combinación entre la subescala de motivación superficial y la estrategia superficial.

Debido a que el análisis factorial es una técnica de reducción de datos que sirve para encontrar grupos homogéneos de variables a partir de un conjunto numeroso de variables, como ya se ha mencionado, ha permitido comprobar en este proyecto que las subescalas establecidas sean homogéneas, al igual que la formación de las variables que se correlacionan mucho entre sí,

\footnotetext{
${ }^{1}$ Se puede consultar el artículo "Evaluación del Modelo Educativo para la formación por competencias laborales en los alumnos de la División de Ingenierías de la Universidad de Guanajuato", de la revista Electrónica sobre Tecnología, Educación y Sociedad, para mayor referencia del análisis seleccionado.
} 


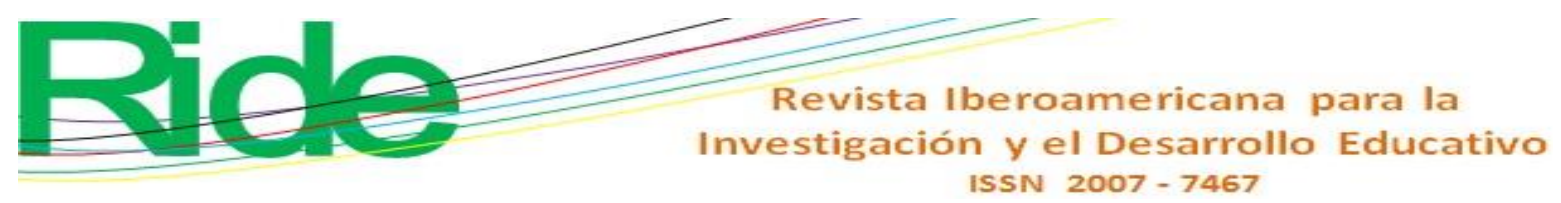

procurando, inicialmente, que las subescalas sean independientes. Al aplicar el análisis factorial a las respuestas de los sujetos se pudo encontrar grupos de variables con significado común y conseguir, de este modo, reducir el número de dimensiones necesarias para explicar las respuestas de los sujetos.

Fundamentalmente, lo que se probó es que con el análisis factorial es posible simplificar la información que proporciona una matriz de correlaciones para hacerla más fácilmente interpretable y que con la aplicación del análisis se logró dicho objetivo.

\section{Percepción de los estudiantes en cuanto a su preparación académica e integral}

En el Modelo Educativo de la UG, el estudiante es el agente principal del proceso educativo, participa activa y responsablemente en la construcción de su aprendizaje y en ambientes que van más allá del aula durante su trayecto formativo universitario (UG, 2011). Con base en ello, se determinan las competencias genéricas que todo universitario debe de adquirir en su proceso educativo en conjunto con las competencias específicas de su carrera profesional.

La variable "competencia genérica" es aplicada en el cuestionario a la muestra de los alumnos de la División de Ingenierías del Campus Guanajuato. Tal instrumento está formado por cuatro partes. La primera consta de dos preguntas tipo Likert; la segunda da a conocer las 30 competencias genéricas implícitas en el documento y solicita al alumno valorar con una escala del 1 al 4 la importancia asignada a cada una de ellas y el nivel de desarrollo adquirido; la tercera parte solicita enumerar del 1 al 5 las competencias consideradas más importantes según prioridad, y la cuarta parte del cuestionario invita a ordenar las 17 competencias genéricas propuestas por psicopedagogos en el instrumento por valoración personal utilizando un ranking que va del 1 al 17.

El cuestionario fue analizado según las partes ya enunciadas que lo constituyen, por lo que se comenzó con la descripción de las dos preguntas iniciales. A su vez, el análisis se realizó en relación con la muestra.

Respecto a la primera pregunta, a saber, “¿Cree que la formación que está recibiendo en la Universidad es adecuada?", $68.10 \%$ de los alumnos eligió la opción "Parcialmente" y $31.90 \%$ la opción "Completamente" (véase tabla 2). 


\section{Revista Iberoamericana para la Investigación y el Desarrollo Educativo \\ ISSN $2007-7467$}

Tabla 2. Percepción de la formación adecuada en la universidad

\begin{tabular}{|c|c|c|c|c|c|}
\hline \multicolumn{2}{|c|}{} & Frecuencia & Porcentaje & $\begin{array}{c}\text { Porcentaje } \\
\text { válido }\end{array}$ & $\begin{array}{c}\text { Porcentaje } \\
\text { acumulado }\end{array}$ \\
\hline \multirow{3}{*}{ Válido } & 1.00 & 840 & 68.1 & 68.1 & 68.1 \\
\cline { 2 - 6 } & 2.00 & 393 & 31.9 & 31.9 & 100.0 \\
\cline { 2 - 6 } & Total & 1233 & 100.0 & 100.0 & \\
\hline
\end{tabular}

Fuente: Elaboración propia

Cabe hacer mención que 68.10 \% de los participantes considera que la formación que está recibiendo en la universidad es adecuada.

Respecto a la segunda pregunta, “¿Conoces las diferentes actividades profesionales de su carrera?", 52.10 \% eligió la opción "Parcialmente", 44.00 \% eligió la opción "Completamente" y 4.00 \% eligió la opción “Casi nada”. De lo anterior se concluye que más de $50 \%$ de los encuestados considera que conoce algunas opciones de las actividades profesionales de su carrera, porcentaje que coincide con exactitud al obtenido en la primera pregunta, referida a la calidad de la formación universitaria recibida, (tabla 3 ).

Tabla 3. Porcentaje del conocimiento de actividades profesionales

\begin{tabular}{|c|c|c|c|c|c|}
\hline \multicolumn{2}{|c|}{} & Frecuencia & Porcentaje & $\begin{array}{c}\text { Porcentaje } \\
\text { válido }\end{array}$ & $\begin{array}{c}\text { Porcentaje } \\
\text { acumulado }\end{array}$ \\
\hline \multirow{4}{*}{ Válido } & 0.00 & 49 & 4.0 & 4.0 & 4.0 \\
\cline { 2 - 6 } & 1.00 & 642 & 52.1 & 52.1 & 56.0 \\
\cline { 2 - 6 } & 2.00 & 542 & 44.0 & 44.0 & 100.0 \\
\cline { 2 - 6 } & Total & 1233 & 100.0 & 100.0 & \\
\hline
\end{tabular}

Fuente: Elaboración propia

Y volviendo a la primera pregunta, la opción "Parcialmente" fue elegida por la mayoría de los alumnos encuestados, como ya se mencionó; pero cabe destacar que las opciones "Casi nada", "Nada" y "No sé" no fueron seleccionadas por ningún alumno. 


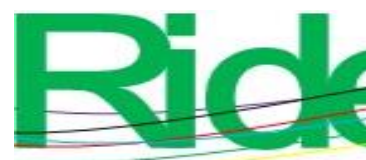

\section{Revista Iberoamericana para la Investigación y el Desarrollo Educativo \\ ISSN 2007 - 7467}

La diferencia de media entre las respuestas de los estudiantes encuestados se comprueba aplicando el estadístico t-Student con un intervalo de confianza de $95 \%$, gracias lo cual se pudo concluir que existen diferencias significativas entre las medias de las respuestas de los estudiantes (tabla 4).

Tabla 4. Prueba de muestra única

\begin{tabular}{|c|c|c|c|c|c|c|}
\hline & \multicolumn{6}{|c|}{ Valor de prueba $=0$} \\
\hline & \multirow[t]{2}{*}{$\mathbf{t}$} & \multirow[t]{2}{*}{ gl } & \multirow{2}{*}{$\begin{array}{c}\text { Sig. } \\
\text { (bilateral) }\end{array}$} & \multirow{2}{*}{$\begin{array}{c}\text { Diferencia de } \\
\text { medias }\end{array}$} & \multicolumn{2}{|c|}{$\begin{array}{l}95 \% \text { de intervalo de } \\
\text { confianza de la diferencia }\end{array}$} \\
\hline & & & & & Inferior & Superior \\
\hline $\begin{array}{c}\text { Pregunta } \\
1\end{array}$ & 99.332 & 1232 & .000 & 1.31873 & 1.2927 & 1.3448 \\
\hline $\begin{array}{c}\text { Pregunta } \\
2\end{array}$ & 86.933 & 1232 & .000 & 1.39984 & 1.3682 & 1.4314 \\
\hline
\end{tabular}

Fuente: Elaboración propia

Al igual que en la primera pregunta, en la segunda pregunta"Nada" y "No sé" no fueron seleccionadas por los alumnos. Y también aquí se deseó conocer si existía diferencia de media entre las respuestas de los estudiantes y se aplicó el estadístico t-Student con un intervalo de confianza de $95 \%$ : los resultados muestran que existen diferencias significativas entre las medias de las respuestas de los estudiantes (ver una vez más la tabla 4).

\section{Percepción de los estudiantes con respecto a las competencias genéricas formativas}

Respecto a la segunda parte del cuestionario, ${ }^{2}$ referida a la presentación de 28 competencias y su respectiva cuantificación del 1 al 4 en función de la importancia dada a cada una de ellas, así como al nivel de desarrollo adquirido, se puede mencionar que en la primera situación (relacionada a la importancia de la competencia), las que presentan las frecuencias más altas y por tanto las mejor valoradas son las siguientes: "Motivación de logro" (987 alumnos), "Mantiene una actitud

\footnotetext{
${ }^{2}$ Los alumnos tenían la posibilidad de seleccionar más de una competencia.
} 


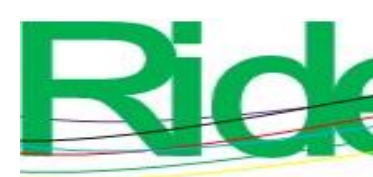

\section{Revista Iberoamericana para la Investigación y el Desarrollo Educativo \\ ISSN 2007 - 7467}

respetuosa hacia la interculturalidad y la diversidad de creencias, valores, ideas y prácticas sociales para promover espacios de convivencia académica y profesional" (939 alumnos), "Toma de decisiones" (938 alumnos), "Compromiso ético" (937 alumnos) y "Preocupación por la calidad" (936 alumnos) (ver tabla 5).

Tabla 5. Competencias genéricas más importantes

\begin{tabular}{|c|l|c|}
\hline Importancia & \multicolumn{1}{|c|}{ Competencia } & $\begin{array}{c}\text { Núm. de } \\
\text { alumnos }\end{array}$ \\
\hline 1 & Motivación de logro & 987 \\
\hline 2 & $\begin{array}{l}\text { Mantiene una actitud respetuosa hacia la interculturalidad y la } \\
\text { diversidad de creencias, valores, ideas y prácticas sociales para } \\
\text { promover espacios de convivencia académica y profesional }\end{array}$ & 939 \\
\hline 3 & Toma de decisiones & 938 \\
\hline 4 & Compromiso ético & 937 \\
\hline 5 & Preocupación por la calidad & 936 \\
\hline
\end{tabular}

Fuente: Elaboración propia

En la segunda situación, en la referida al nivel de desarrollo adquirido, las competencias con las frecuencias más altas son "Motivación de logro" (640 alumnos), "Compromiso ético" (640 alumnos), "Preocupación por la calidad" (639 alumnos), "Iniciativa y espíritu emprendedor" (590 alumnos) y "Capacidad para adaptarse a nuevas situaciones" (493 alumnos) (consultar tabla 6).

Tabla 6. Competencias genéricas con mayor nivel de desarrollo

\begin{tabular}{|c|l|c|}
\hline Importancia & \multicolumn{1}{|c|}{ Competencia } & Núm. de alumnos \\
\hline 1 & Motivación de logro & 640 \\
\hline 2 & Compromiso ético & 640 \\
\hline 3 & Preocupación por la calidad & 639 \\
\hline 4 & Iniciativa y espíritu emprendedor & 590 \\
\hline 5 & Capacidad para adaptarse a nuevas situaciones & 493 \\
\hline
\end{tabular}

Fuente: Elaboración propia 


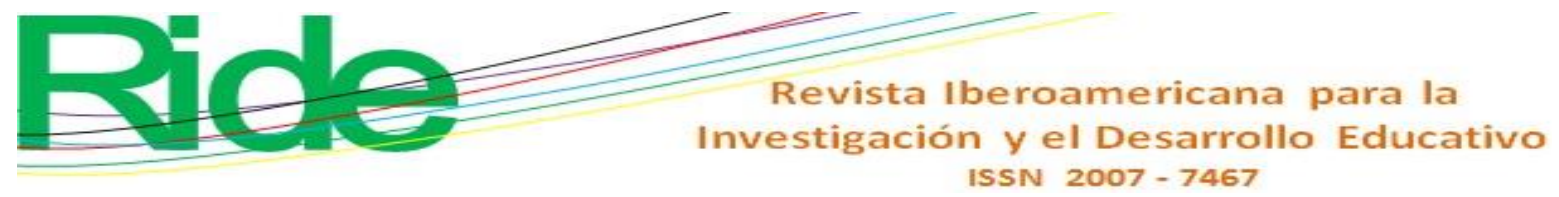

Es de destacar que las competencias "Motivación de logro", "Compromiso ético" y "Preocupación por la calidad" están dentro de las cinco preferidas en ambos casos.

De igual forma que en el aparado anterior, se quiso comprobar la existencia de diferencias entre las respuestas de los participantes, por lo cual se llevó a cabo la comparación de medias a través del estadístico $\mathrm{t}-$ Student para muestras independientes con un intervalo de confianza de 9 $5 \%$ (tabla 7 ).

Tabla 7. Prueba de muestra única*

\begin{tabular}{|c|c|c|c|c|c|c|}
\hline \multirow{3}{*}{ Habilidad/Competencia } & \multicolumn{6}{|c|}{ Valor de prueba $=0$} \\
\hline & \multirow[t]{2}{*}{$\mathbf{t}$} & \multirow[t]{2}{*}{ gl } & \multirow[t]{2}{*}{$\begin{array}{c}\text { Sig. } \\
\text { (bilateral) }\end{array}$} & \multirow[t]{2}{*}{$\begin{array}{l}\text { Diferencia } \\
\text { de medias }\end{array}$} & \multicolumn{2}{|c|}{$\begin{array}{l}\text { 95\% de intervalo de } \\
\text { confianza de la } \\
\text { diferencia }\end{array}$} \\
\hline & & & & & Inferior & Superior \\
\hline $\begin{array}{l}\text { Planifica su proyecto educativo y de vida de manera } \\
\text { autónoma bajo los principios de libertad, respeto, } \\
\text { responsabilidad social y justicia para contribuir como } \\
\text { agente de cambio al desarrollo de su } \\
\text { entorno/Importancia }\end{array}$ & 237.246 & 1232 & 0 & 3.6813 & 3.6508 & 3.7117 \\
\hline $\begin{array}{l}\text { Planifica su proyecto educativo y de vida de manera } \\
\text { autónoma bajo los principios de libertad, respeto, } \\
\text { responsabilidad social y justicia para contribuir como } \\
\text { agente de cambio al desarrollo de su entorno/Nivel }\end{array}$ & 221.291 & 1232 & 0 & 3.2417 & 3.2129 & 3.2704 \\
\hline $\begin{array}{l}\text { Se comunica de manera oral y escrita en español y en } \\
\text { una lengua extranjera para ampliar sus redes } \\
\text { académicas, sociales y profesionales que le permitan } \\
\text { adquirir una perspectiva internacional/Importancia }\end{array}$ & 135.985 & 1232 & 0 & 3.4818 & 3.4315 & 3.5320 \\
\hline $\begin{array}{l}\text { Se comunica de manera oral y escrita en español y en } \\
\text { una lengua extranjera para ampliar sus redes } \\
\text { académicas, sociales y profesionales que le permitan } \\
\text { adquirir una perspectiva internacional/Nivel }\end{array}$ & 101.782 & 1232 & 0 & 2.4769 & 2.4291 & 2.5246 \\
\hline $\begin{array}{l}\text { Maneja ética y responsablemente las tecnologías de } \\
\text { la información para agilizar sus procesos académicos } \\
\text { y profesionales de intercomunicación/Importancia }\end{array}$ & 159.075 & 1232 & 0 & 3.3998 & 3.3579 & 3.4418 \\
\hline $\begin{array}{l}\text { Maneja ética y responsablemente las tecnologías de } \\
\text { la información para agilizar sus procesos académicos } \\
\text { y profesionales de intercomunicación/Nivel }\end{array}$ & 144.266 & 1232 & 0 & 2.9586 & 2.9184 & 2.9989 \\
\hline
\end{tabular}




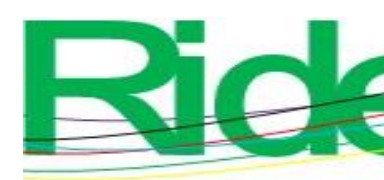

Revista Iberoamericana para la

Investigación y el Desarrollo Educativo

ISSN 2007 - 7467

\begin{tabular}{|c|c|c|c|c|c|c|}
\hline $\begin{array}{l}\text { Sustenta una postura personal sobre temas de interés } \\
\text { y relevancia general, considerando otros puntos de } \\
\text { vista de manera crítica, respetuosa y } \\
\text { reflexiva/Importancia }\end{array}$ & 218.390 & 1232 & 0 & 3.5604 & 3.5284 & 3.5924 \\
\hline $\begin{array}{l}\text { Sustenta una postura personal sobre temas de interés } \\
\text { y relevancia general, considerando otros puntos de } \\
\text { vista de manera crítica, respetuosa y reflexiva/Nivel }\end{array}$ & 172.379 & 1232 & 0 & 3.0803 & 3.0452 & 3.1153 \\
\hline $\begin{array}{l}\text { Elige y practica estilos de vida saludables que le } \\
\text { permiten un desempeño académico y profesional } \\
\text { equilibrado/Importancia }\end{array}$ & 193.338 & 1232 & 0 & 3.5207 & 3.4850 & 3.5564 \\
\hline $\begin{array}{l}\text { Elige y practica estilos de vida saludables que le } \\
\text { permiten un desempeño académico y profesional } \\
\text { equilibrado/Nivel }\end{array}$ & 109.944 & 1232 & 0 & 2.7972 & 2.7473 & 2.8472 \\
\hline $\begin{array}{l}\text { Mantiene una actitud respetuosa hacia la } \\
\text { interculturalidad y la diversidad de creencias, } \\
\text { valores, ideas y prácticas sociales para promover } \\
\text { espacios de convivencia académica y } \\
\text { profesional/Importancia }\end{array}$ & 246.755 & 1232 & 0 & 3.7218 & 3.6922 & 3.7514 \\
\hline $\begin{array}{l}\text { Mantiene una actitud respetuosa hacia la } \\
\text { interculturalidad y la diversidad de creencias, } \\
\text { valores, ideas y prácticas sociales para promover } \\
\text { espacios de convivencia académica y } \\
\text { profesional/Nivel }\end{array}$ & 161.947 & 1232 & 0 & 3.1995 & 3.1608 & 3.2383 \\
\hline $\begin{array}{l}\text { Es sensible al arte y participa en la apreciación e } \\
\text { interpretación de sus expresiones en distintos géneros } \\
\text { que promuevan su formación integral/Importancia }\end{array}$ & 133.283 & 1232 & 0 & 3.1606 & 3.1141 & 3.2071 \\
\hline $\begin{array}{l}\text { Es sensible al arte y participa en la apreciación e } \\
\text { interpretación de sus expresiones en distintos géneros } \\
\text { que promuevan su formación integral/Nivel }\end{array}$ & 87.744 & 1232 & 0 & 2.5572 & 2.5000 & 2.6144 \\
\hline Habilidades de investigación/Importancia & 174.922 & 1232 & 0 & 3.4818 & 3.4427 & 3.5208 \\
\hline Habilidades de investigación/Nivel & 132.079 & 1232 & 0 & 2.8800 & 2.8372 & 2.9227 \\
\hline $\begin{array}{l}\text { Habilidades de gestión de la información (habilidad } \\
\text { para buscar y analizar información proveniente de } \\
\text { fuentes diversas)/Importancia }\end{array}$ & 228.766 & 1232 & 0 & 3.6391 & 3.6079 & 3.6703 \\
\hline $\begin{array}{l}\text { Habilidades de gestión de la información (habilidad } \\
\text { para buscar y analizar información proveniente de } \\
\text { fuentes diversas)/Nivel }\end{array}$ & 144.266 & 1232 & 0 & 2.9586 & 2.9184 & 2.9989 \\
\hline $\begin{array}{l}\text { Capacidad crítica } \\
\text { propositiva/Importancia }\end{array}$ & 266.534 & 1232 & 0 & 3.6415 & 3.6147 & 3.6683 \\
\hline
\end{tabular}




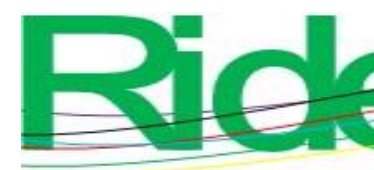

Revista Iberoamericana para la

Investigación y el Desarrollo Educativo

ISSN $2007-7467$

\begin{tabular}{|c|c|c|c|c|c|c|}
\hline Capacidad crítica y autocrítica propositiva/Nivel & 167.788 & 1232 & 0 & 3.1184 & 3.0819 & 3.1549 \\
\hline $\begin{array}{l}\text { Capacidad para adaptarse a nuevas } \\
\text { situaciones/Importancia }\end{array}$ & 237.246 & 1232 & 0 & 3.6813 & 3.6508 & 3.7117 \\
\hline Capacidad para adaptarse a nuevas situaciones/Nivel & 172.661 & 1232 & 0 & 3.2782 & 3.2409 & 3.3154 \\
\hline $\begin{array}{l}\text { Capacidad para generar nuevas ideas } \\
(\text { creatividad)/Importancia }\end{array}$ & 229.906 & 1232 & 0 & 3.6423 & 3.6113 & 3.6734 \\
\hline $\begin{array}{lrll}\text { Capacidad para } & \text { generar nuevas } & \text { ideas } \\
(\text { creatividad)/Nivel } & & & \end{array}$ & 153.635 & 1232 & 0 & 3.1168 & 3.0770 & 3.1566 \\
\hline Resolución de problemas/Importancia & 277.287 & 1232 & 0 & 3.6813 & 3.6552 & 3.7073 \\
\hline Resolución de problemas/Nivel & 156.513 & 1232 & 0 & 3.0762 & 3.0377 & 3.1148 \\
\hline Toma de decisiones/Importancia & 246.543 & 1232 & 0 & 3.7210 & 3.6914 & 3.7506 \\
\hline Toma de decisiones/Nivel & 122.472 & 1232 & 0 & 3.0373 & 2.9887 & 3.0860 \\
\hline Trabajo en equipo/Importancia & 258.105 & 1232 & 0 & 3.6010 & 3.5736 & 3.6283 \\
\hline Trabajo en equipo/Nivel & 162.332 & 1232 & 0 & 3.2028 & 3.1640 & 3.2415 \\
\hline
\end{tabular}

* Importancia se refiere a la percepción que tiene el alumno de la competencia o habilidad para el ejercicio de tu profesión y Nivel se refiere a la percepción que tiene el alumno de la habilidad o competencia que ha desarrollado durante sus estudios en la universidad.

Fuente: Elaboración propia

\section{Preferencia de los estudiantes con respecto a las 28 competencias genéricas formativas}

Respecto a la tercera parte del cuestionario, vinculada a la elección y ordenación de las cinco competencias que se consideran más importantes según la opinión del estudiante, los resultados son los siguientes: "Liderazgo" (196 alumnos), "Resolución de problemas" (196 alumnos), "Capacidad para generar nuevas ideas (creatividad)" (200 alumnos), "Toma de decisiones" (150 alumnos) y "Capacidad para comunicarse con personas no expertas en la materia", (100 alumnos) (véase tabla 8). 

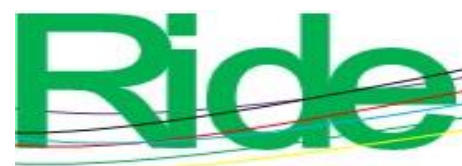

Revista Iberoamericana para la Investigación y el Desarrollo Educativo

ISSN 2007 - 7467

Tabla 8. Prioridad de las cinco competencias principales

\begin{tabular}{|c|l|c|}
\hline Importancia & \multicolumn{1}{|c|}{ Competencia } & $\begin{array}{c}\text { Núm. de } \\
\text { alumnos }\end{array}$ \\
\hline 1 & Liderazgo & 196 \\
\hline 2 & Resolución de problemas & 196 \\
\hline 3 & Capacidad para generar nuevas ideas (creatividad) & 200 \\
\hline 4 & Toma de decisiones & 150 \\
\hline 5 & $\begin{array}{l}\text { Capacidad para comunicarse con personas no expertas en la } \\
\text { materia }\end{array}$ & 100 \\
\hline
\end{tabular}

Fuente: Elaboración propia

Una vez más, se comprobó la existencia de diferencias entre las respuestas de los participantes mediante la comparación de medias a través del estadístico t-Student para muestras independientes con un intervalo de confianza de $95 \%$ (tabla 9). 


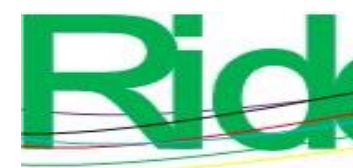

Revista Iberoamericana para la Investigación y el Desarrollo Educativo

ISSN 2007 - 7467

Tabla 9. Prueba de muestra única*

\begin{tabular}{|c|c|c|c|c|c|c|}
\hline \multirow{3}{*}{ Importancia } & \multicolumn{6}{|c|}{ Valor de prueba $=0$} \\
\hline & \multirow[t]{2}{*}{$\mathbf{T}$} & \multirow[t]{2}{*}{ gl } & \multirow[t]{2}{*}{$\begin{array}{c}\text { Sig. } \\
\text { (bilateral) }\end{array}$} & \multirow[t]{2}{*}{$\begin{array}{r}\text { Diferencia } \\
\text { de medias }\end{array}$} & \multicolumn{2}{|c|}{$\begin{array}{l}\text { 95\% de intervalo de } \\
\text { confianza de la } \\
\text { diferencia }\end{array}$} \\
\hline & & & & & Inferior & Superior \\
\hline Liderazgo & 70.311 & 1183 & .000 & 12.17314 & 11.8335 & 12.5128 \\
\hline $\begin{array}{ll}\text { Resolución } & \text { de } \\
\text { problemas } & \end{array}$ & 55.768 & 1183 & .000 & 10.25338 & 9.8927 & 10.6141 \\
\hline $\begin{array}{lr}\begin{array}{l}\text { Capacidad } \\
\text { generar }\end{array} \text { nuevas } \\
\text { ideas (creatividad) }\end{array}$ & 91.705 & 1183 & .000 & 14.12500 & 13.8228 & 14.4272 \\
\hline $\begin{array}{ll}\text { Toma } & \mathrm{de} \\
\text { decisiones } & \end{array}$ & 52.308 & 1183 & .000 & 13.73733 & 13.2221 & 14.2526 \\
\hline $\begin{array}{lr}\text { Capacidad } & \text { para } \\
\text { comunicarse } & \text { con } \\
\text { personas } & \text { no } \\
\text { expertas en } & \text { la } \\
\text { materia } & \\
\end{array}$ & 64.080 & 1183 & . 000 & 13.67399 & 13.2553 & 14.0927 \\
\hline
\end{tabular}

Fuente: Elaboración propia

Orden jerárquico de las 17 competencias que han sido consideradas como las más importantes para el desarrollo profesional de los ingenieros

Respecto a la cuarta parte del cuestionario, referida al orden jerárquico de las 17 competencias que han sido consideradas como las más importantes para el desarrollo profesional de los ingenieros, los resultados son los mostrados en la tabla 10. 
Tabla 10. Orden jerárquico de las 17 competencias principales

\begin{tabular}{|c|l|c|}
\hline Prioridad & \multicolumn{1}{|c|}{ Competencia } & Núm. de alumnos \\
\hline $\mathbf{1}$ & Habilidades de investigaciones & 495 \\
\hline $\mathbf{2}$ & Habilidades interpersonales & 298 \\
\hline $\mathbf{3}$ & $\begin{array}{l}\text { Conocimientos generales básicos en el área de } \\
\text { estudio }\end{array}$ & 297 \\
\hline $\mathbf{4}$ & $\begin{array}{l}\text { Capacidad de aplicar los conocimientos en la } \\
\text { práctica }\end{array}$ & 296 \\
\hline $\mathbf{5}$ & Capacidad de trabajar en un equipo interdisciplinar & 248 \\
\hline $\mathbf{6}$ & Iniciativa y espíritu emprendedor & 247 \\
\hline $\mathbf{7}$ & Capacidad de análisis y síntesis & 245 \\
\hline $\mathbf{8}$ & Capacidad de aprender & 199 \\
\hline $\mathbf{9}$ & Capacidad para generar nuevas ideas (creatividad) & 198 \\
\hline $\mathbf{1 0}$ & Conocimientos de una segunda lengua & 198 \\
\hline $\mathbf{1 1}$ & Conocimientos básicos de la profesión & 197 \\
\hline $\mathbf{1 2}$ & Toma de decisiones & 196 \\
\hline $\mathbf{1 3}$ & Capacidad crítica y autocrítica & 150 \\
\hline $\mathbf{1 4}$ & Compromiso ético & 148 \\
\hline $\mathbf{1 5}$ & Comunicación oral y escrita de la propia lengua & 50 \\
\hline $\mathbf{1 6}$ & Apreciación de la diversidad y multiculturalidad & 100 \\
\hline $\mathbf{1 7}$ & Capacidad para adaptarse a nuevas situaciones & \\
\hline
\end{tabular}

Fuente: Elaboración propia

Aquí también se llevó a cabo la comparación de medias a través del estadístico t-Student para muestras independientes con un intervalo de confianza de $95 \%$ y los datos resultantes se muestran en la tabla 11. 


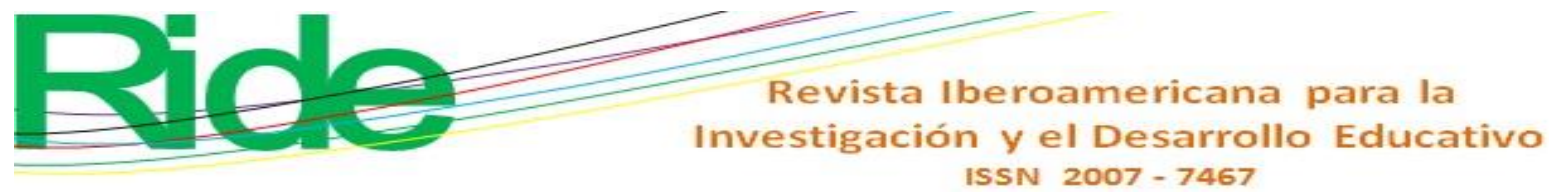

Tabla 11. Prueba de muestra única

\begin{tabular}{|c|c|c|c|c|c|c|}
\hline \multirow{3}{*}{ Habilidad/Competencia } & \multicolumn{6}{|c|}{ Valor de prueba $=0$} \\
\hline & \multirow[t]{2}{*}{$\mathbf{t}$} & \multirow[t]{2}{*}{ gl } & \multirow[t]{2}{*}{$\begin{array}{c}\text { Sig. } \\
\text { (bilateral) }\end{array}$} & \multirow[t]{2}{*}{$\begin{array}{l}\text { Diferencia } \\
\text { de medias }\end{array}$} & \multicolumn{2}{|c|}{$\begin{array}{c}95 \% \text { de intervalo de } \\
\text { confianza de la } \\
\text { diferencia }\end{array}$} \\
\hline & & & & & Inferior & Superior \\
\hline $\begin{array}{l}\text { Capacidad de trabajar en un equipo } \\
\text { interdisciplinar }\end{array}$ & 55.593 & 1183 & 0 & 7.2931 & 7.0357 & 7.5505 \\
\hline Apreciación de la diversidad y multiculturalidad & 85.875 & 1183 & 0 & 12.6453 & 12.3564 & 12.9342 \\
\hline $\begin{array}{l}\text { Conocimientos generales básicos en el área de } \\
\text { estudio }\end{array}$ & 48.852 & 1183 & 0 & 6.3547 & 6.0995 & 6.6099 \\
\hline Conocimientos básicos de la profesión & 48.071 & 1183 & 0 & 6.1613 & 5.9098 & 6.4128 \\
\hline Capacidad de análisis y síntesis & 75.743 & 1183 & 0 & 9.7576 & 9.5049 & 10.0104 \\
\hline $\begin{array}{l}\text { Capacidad de aplicar los conocimientos en la } \\
\text { práctica }\end{array}$ & 45.837 & 1183 & 0 & 5.6951 & 5.4513 & 5.9389 \\
\hline $\begin{array}{l}\text { Capacidad para generar nuevas ideas } \\
\text { (creatividad) }\end{array}$ & 50.785 & 1183 & 0 & 5.3767 & 5.1690 & 5.5844 \\
\hline Capacidad para adaptarse a nuevas situaciones & 76.648 & 1183 & 0 & 8.0743 & 7.8676 & 8.2810 \\
\hline Capacidad de aprender & 62.306 & 1183 & 0 & 8.0845 & 7.8299 & 8.3390 \\
\hline Capacidad crítica y autocrítica & 89.045 & 1183 & 0 & 10.7931 & 10.5553 & 11.0309 \\
\hline Toma de decisiones & 55.697 & 1183 & 0 & 6.9569 & 6.7119 & 7.2020 \\
\hline Iniciativa y espíritu emprendedor & 80.269 & 1183 & 0 & 10.7162 & 10.4543 & 10.9781 \\
\hline Compromiso ético & 72.178 & 1183 & 0 & 10.1292 & 9.8539 & 10.4046 \\
\hline Habilidades interpersonales & 111.844 & 1183 & 0 & 11.9671 & 11.7571 & 12.1770 \\
\hline Conocimientos de una segunda lengua & 107.524 & 1183 & 0 & 11.4046 & 11.1965 & 11.6127 \\
\hline Comunicación oral y escrita de la propia lengua & 122.784 & 1183 & 0 & 12.4654 & 12.2662 & 12.6646 \\
\hline Habilidades para la investigación & 64.434 & 1183 & 0 & 9.2078 & 8.9274 & 9.4881 \\
\hline Habilidades interpersonales/Importancia & 243.606 & 1232 & 0 & 3.3998 & 3.3725 & 3.4272 \\
\hline Habilidades interpersonales/Nivel & 155.325 & 1232 & 0 & 2.7997 & 2.7643 & 2.8350 \\
\hline Liderazgo/Importancia & 189.656 & 1232 & 0 & 3.4404 & 3.4048 & 3.4760 \\
\hline Liderazgo/Nivel & 109.489 & 1232 & 0 & 2.9157 & 2.8634 & 2.9679 \\
\hline $\begin{array}{l}\text { Capacidad de trabajar en un equipo } \\
\text { interdisciplinar/Importancia }\end{array}$ & 237.246 & 1232 & 0 & 3.6813 & 3.6508 & 3.7117 \\
\hline $\begin{array}{l}\text { Capacidad de trabajar en un equipo } \\
\text { interdisciplinar/Nivel }\end{array}$ & 131.577 & 1232 & 0 & 2.9968 & 2.9521 & 3.0414 \\
\hline $\begin{array}{l}\text { Capacidad para comunicarse con personas no } \\
\text { expertas en la materia/Importancia }\end{array}$ & 212.974 & 1232 & 0 & 3.4809 & 3.4489 & 3.5130 \\
\hline
\end{tabular}




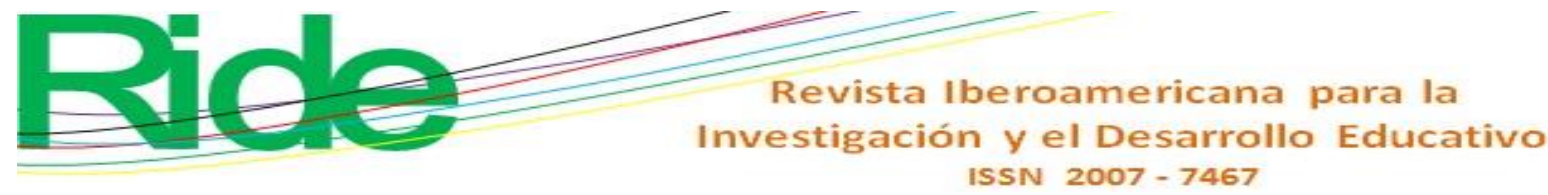

\begin{tabular}{|c|c|c|c|c|c|c|}
\hline $\begin{array}{l}\text { Capacidad para comunicarse con personas no } \\
\text { expertas en la materia/Nivel }\end{array}$ & 123.632 & 1232 & 0 & 2.9976 & 2.9500 & 3.0451 \\
\hline $\begin{array}{l}\text { Apreciación de la diversidad } \quad \text { y } \\
\text { multiculturalidad/Importancia }\end{array}$ & 218.226 & 1232 & 0 & 3.5588 & 3.5268 & 3.5908 \\
\hline $\begin{array}{l}\text { Apreciación de la diversidad } \quad \text { y } \\
\text { multiculturalidad/Nivel }\end{array}$ & 126.886 & 1232 & 0 & 2.7567 & 2.7141 & 2.7993 \\
\hline $\begin{array}{l}\text { Habilidad para trabajar en un contexto } \\
\text { internacional/Importancia }\end{array}$ & 223.684 & 1232 & 0 & 3.6010 & 3.5694 & 3.6326 \\
\hline $\begin{array}{l}\text { Habilidad para trabajar en un contexto } \\
\text { internacional/Nivel }\end{array}$ & 107.856 & 1232 & 0 & 2.4777 & 2.4326 & 2.5228 \\
\hline $\begin{array}{l}\text { Conocimiento de culturas y costumbres de otros } \\
\text { países/Importancia }\end{array}$ & 164.168 & 1232 & 0 & 3.1582 & 3.1204 & 3.1959 \\
\hline $\begin{array}{l}\text { Conocimiento de culturas y costumbres de otros } \\
\text { países/Nivel }\end{array}$ & 106.347 & 1232 & 0 & 2.4363 & 2.3914 & 2.4813 \\
\hline $\begin{array}{l}\text { Habilidad para trabajar de forma } \\
\text { autónoma/Importancia }\end{array}$ & 237.246 & 1232 & 0 & 3.6813 & 3.6508 & 3.7117 \\
\hline $\begin{array}{l}\text { Habilidad para trabajar de forma } \\
\text { autónoma/Nivel }\end{array}$ & 123.780 & 1232 & 0 & 2.8759 & 2.8303 & 2.9215 \\
\hline Diseño y gestión de proyectos/Importancia & 258.105 & 1232 & 0 & 3.6010 & 3.5736 & 3.6283 \\
\hline Diseño y gestión de proyectos/Nivel & 145.203 & 1232 & 0 & 3.0779 & 3.0363 & 3.1194 \\
\hline Iniciativa y espíritu emprendedor/Importancia & 218.226 & 1232 & 0 & 3.5588 & 3.5268 & 3.5908 \\
\hline Iniciativa y espíritu emprendedor/Nivel & 125.051 & 1232 & 0 & 3.1955 & 3.1453 & 3.2456 \\
\hline Compromiso ético/Importancia & 308.982 & 1232 & 0 & 3.7599 & 3.7361 & 3.7838 \\
\hline Compromiso ético/Nivel & 189.234 & 1232 & 0 & 3.4388 & 3.4031 & 3.4744 \\
\hline Preocupación por la calidad/Importancia & 308.560 & 1232 & 0 & 3.7591 & 3.7352 & 3.7830 \\
\hline Preocupación por la calidad/Nivel & 131.388 & 1232 & 0 & 3.2758 & 3.2268 & 3.3247 \\
\hline Motivación de logro/Importancia & 333.796 & 1232 & 0 & 3.8005 & 3.7781 & 3.8228 \\
\hline Motivación de logro/Nivel & 158.788 & 1232 & 0 & 3.3585 & 3.3170 & 3.4000 \\
\hline
\end{tabular}

* Importancia se refiere a la percepción que tiene el alumno de la competencia o habilidad para el ejercicio de tu profesión y Nivel se refiere a la percepción que tiene el alumno de la habilidad o competencia que ha desarrollado durante sus estudios en la universidad.

Fuente: Elaboración propia 


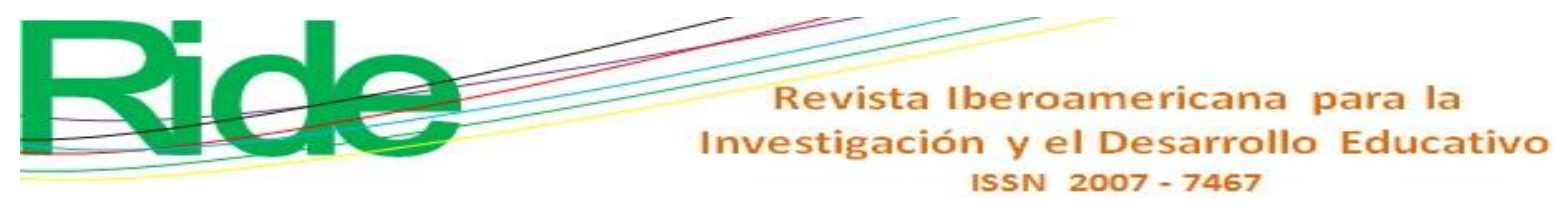

\section{Resultados y discusión}

Con base en el análisis efectuado en la investigación, se determinó que $90 \%$ de alumnado adopta predominantemente el enfoque profundo, es decir, que al momento de comprender los contenidos y trabajos propuestos en clase no escatima en esfuerzos y utiliza estrategias que le permiten relacionar los contenidos nuevos con los contenidos previos y comprobar la relación entre los cursos y su avance académico planteado.

En cuanto al enfoque predominantemente superficial, solo es adoptado por $6 \%$ del alumnado. Esto es: un porcentaje muy bajo de la muestra participante está interesados por aprobar las asignaturas sin intención de comprender la práctica y los contenidos, llevando a cabo un mínimo esfuerzo, razón por la cual utilizan fundamentalmente la memorización y la reproducción automática como estrategias de aprendizaje, tomando en cuenta solamente los contenidos y materiales proporcionados por el profesor en las sesiones de clases.

Por otra parte, se destaca la existencia de $4 \%$ del alumnado cuyo enfoque de aprendizaje no está definido. De acuerdo a los resultados, este grupo de alumnos posee una motivación más profunda que superficial, mientras que utiliza estrategias superficiales y profundas de manera indistinta. Es un grupo de alumnos que busca la comprensión de los contenidos de las materias cursadas, pero a través únicamente del material entregado por el profesor en clases. Por tanto, se despreocupa de ampliar el material por iniciativa propia (García, 2004). Se determinan varias coincidencias entre las características manifestadas por este grupo de alumnos con el enfoque denominado comprensión y memorización, al considerar que los enfoques que adopta el alumnado se encuentran en un continuo cambio que depende del avance escolar (Hernández, García, Martínez, Hervás y Maquilón, 2002).

El proceso de la investigación muestra diferencias significativas respecto al enfoque de aprendizaje adoptado por los alumnos de la División de Ingenierías del Campus Guanajuato de la Universidad de Guanajuato. No obstante, coincide en que las medias más altas se encuentran en un enfoque profundo.

Respecto a la correlación de las subescalas implícitas en los enfoques de aprendizaje, se puede inferir que, en la muestra global, los motivos profundos se correlacionaron significativamente con las estrategias profundas, no así con las estrategias superficiales. Asimismo, los motivos superficiales correlacionaron con las estrategias superficiales. 


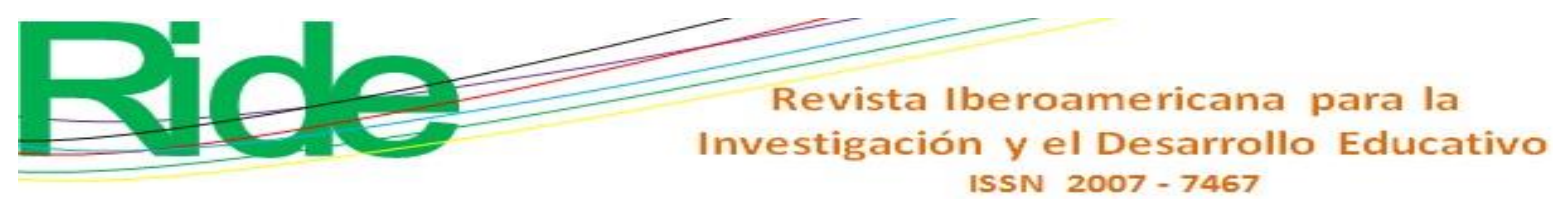

En lo que respecta a las competencias genéricas, el instrumento utilizado estuvo constituido por cuatro partes, las que se explican con precisión en el apartado correspondiente. Cada una de ellas presentó un formato distinto en cuanto a indagación de respuestas, por lo que el análisis se realizó en función a ello y por consiguiente el orden sugerido. A continuación una recapitulación de los resultados obtenidos.

Con relación a la primera pregunta,“¿Cree que la formación que está recibiendo en la Universidad es adecuada?”, $68.10 \%$ de los estudiantes encuestados siente que está recibiendo una formación universitaria "Parcial" y 31.90 \% menciona recibir una formación "Completa". Por lo tanto, se requiere realizar un plan de acción para dar a conocer a los estudiantes en forma amplia qué tipo de formación están recibiendo como universitarios, así como dónde y cómo poner en práctica dicha formación.

En cuanto a la segunda pregunta. “¿Cómo valora las posibles salidas profesionales de su carrera?", $52.10 \%$ de los alumnos consideró que tiene "Parcialmente" salidas profesionales, $44 \%$ coincide en "Completamente" y $4 \%$ optó por la opción "Casi nada". Por consiguiente, y de acuerdo a los resultados analíticos, más de $50 \%$ de los encuestados considera que conoce algunas opciones de las actividades profesionales de su carrera. En consecuencia, se requiere de un plan estratégico en coordinación con los empleadores de los egresados de los programas educativos de la División de Ingenierías del Campus Guanajuato para que los alumnos conozcan las actividades profesionales y sus áreas de oportunidad, planteando entre varias estrategias las prácticas que puedan realizar en el sector productivo respectivo.

Ahora bien, de la segunda parte del cuestionario, referida a la presentación de 28 competencias y su respectiva cuantificación del 1 al 4 en función de la importancia dada a cada una de ellas y al nivel de desarrollo adquirido, se infiere que en la primera situación las competencias que presentan las medias más altas y, por tanto, las mejor cuantificadas son "Motivación del logro" $(\chi=3.80)$, "Compromiso ético" $(\chi=3.76)$, "Preocupación por la calidad" $(\chi=3.76)$, "Mantiene una actitud respetuosa hacia la interculturalidad y la diversidad de creencias, valores, ideas y prácticas sociales para promover espacios de convivencia académica y profesional" $(\chi=3.72)$ y "Toma de decisiones $(\chi=3.72)$. 


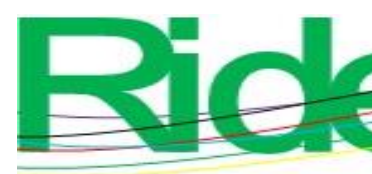

\section{Revista Iberoamericana para la Investigación y el Desarrollo Educativo \\ ISSN $2007-7467$}

En el segundo contexto, la referida al nivel de desarrollo adquirido, las competencias con las medias más altas son "Compromiso ético" $(\chi=3.44)$, "Motivación de logro" $(\chi=3.36)$, "Capacidad para adaptarse a nuevas situaciones" $(\chi=3.28)$, "Preocupación por la calidad" $(\chi=$ 3.27) y "Planifica su proyecto educativo y de vida de manera autónoma bajo los principios de libertad, respeto, responsabilidad social y justicia para contribuir como agente de cambio al desarrollo de su entorno" $(\chi=3.24)$. Es preciso destacar que "Compromiso ético" y "Motivación del logro" están dentro de las cinco preferidas en ambos casos.

De la tercera parte del cuestionario, referida a las cinco prioridades relativas a las 28 competencias genéricas presentadas, cabe recalcar que la competencia "Capacidad para generar nuevas ideas (creatividad)" presenta una frecuencia de $16.66 \%$, seguida de las competencias "Liderazgo" y "Resolución de problemas" con una frecuencia de 16.33 \% y "Toma de decisiones" con $12.50 \%$; finalmente se ubica la competencia "Capacidad para comunicarse con personas no expertas en la materia" con una frecuencia de $8.33 \%$.

Relacionado con la cuarta parte del cuestionario, concerniente a la categorización de 17 competencias seleccionadas por los alumnos, el orden de prioridades queda de la forma siguiente:

1. "Habilidades de investigaciones" con 495 preferencias.

2. “Habilidades interpersonales" con 298 preferencias.

3. “Conocimientos generales básicos en el área de estudio" con 297 preferencias.

4. "Capacidad de aplicar los conocimientos en la práctica" con 296 preferencias.

5. “Capacidad de trabajar en un equipo interdisciplinar" con 248 preferencias.

6. "Iniciativa y espíritu emprendedor" con 247 preferencias.

7. “Capacidad de análisis y síntesis” con 245 preferencias.

8. “Capacidad de aprender" con 199 preferencias.

9. “Capacidad para generar nuevas ideas (creatividad)" con 198 preferencias.

10. "Conocimientos de una segunda lengua" con 198 preferencias.

11. “Conocimientos básicos de la profesión” con 197 preferencias.

12. “Toma de decisiones" con 197 preferencias.

13. "Capacidad crítica y autocrítica" con 196 preferencias.

14. "Compromiso ético" con 150 preferencias.

15. "Comunicación oral y escrita de la propia lengua" con 148 preferencias. 

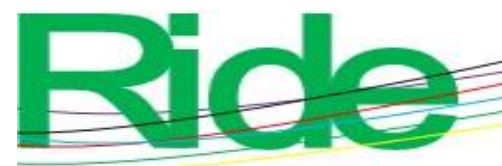

Revista Iberoamericana para la Investigación y el Desarrollo Educativo ISSN $2007-7467$

16. “Apreciación de la diversidad y multiculturalidad” con 100 preferencias.

17. “Capacidad para adaptarse a nuevas situaciones” con 50 preferencias.

Respecto al rendimiento académico, $15.41 \%$ de los alumnos de ingenierías tiene un rendimiento académico "Regular y malo" (calificaciones que oscilan entre 5.0 y 7.5 ) y $84.49 \%$ tiene un rendimiento "Muy bueno y bueno" (calificaciones que oscilan entre 7.6 y 10.0). ${ }^{3}$

En relación con la determinación de las correlaciones entre los enfoques de aprendizaje, las competencias genéricas y el rendimiento académico de los alumnos, se puede inferir que el rendimiento académico correlaciona positivamente con los enfoques de aprendizaje, con la "Importancia" y el "Nivel" de las competencias genéricas. Los enfoques de aprendizaje correlacionan positivamente con el rendimiento académico, con la "Importancia" y "Nivel" de las competencias genéricas.

La "Importancia" de las competencias genéricas correlaciona positivamente con el rendimiento académico, los enfoques de aprendizaje y el "Nivel" de las competencias genéricas. El "Nivel" de las competencias genéricas correlaciona de manera positiva con el rendimiento académico, con la "Importancia" de ellas y con los enfoques de aprendizaje. Por consiguiente, existe correlación positiva entre los enfoques de aprendizaje, las competencias genéricas y el rendimiento académico.

\section{Reflexiones finales}

En el presente proyecto los instrumentos utilizados (cuestionario, entrevista y observación) fueron apropiados para la medición de los enfoques de aprendizaje, ya que fueron validados por una muestra de control. Los resultados obtenidos reflejan una estructura adecuada de los instrumentos debido a que las subescalas se agruparon apropiadamente en los diferentes enfoques. Por su parte, los valores del alfa de Cronbach obtenidos en las tres principales escalas están entre 0.490 y 0.820 , lo cual indica niveles altos de consistencia interna. En referencia a las subescalas, también se observa que los resultados son muy parecidos a los del mismo instrumento.

\footnotetext{
${ }^{3}$ Datos proporcionados por la Dirección de Asuntos Académico del Campus Guanajuato de la UG (junio 2016).
} 


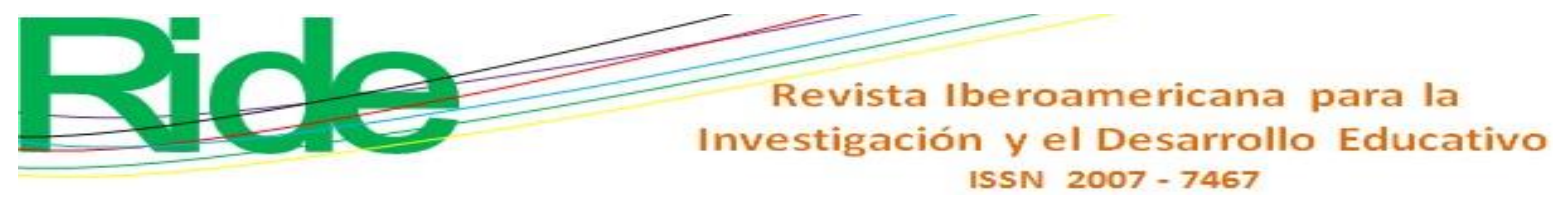

En relación con el segundo objetivo, se obtiene que el enfoque preferido por los estudiantes es el profundo. El hecho de que $90 \%$ de la muestra haya adoptado el enfoque profundo indica un aspecto alentador en cuanto a la mayor motivación y utilización de estrategias de más alto nivel; es decir, un proceso de aprendizaje de mayor calidad, lo que es deseable en el contexto universitario.

Para determinar el efecto de los resultados de la presente investigación sobre la práctica docente, se pueden distinguir dos etapas principales en el análisis de la implantación del Modelo Educativo: una a priori y otra a posteriori. El efecto a priori del Modelo Educativo, es decir, antes de entenderlo, aceptarlo y decidirse a aplicarlo en la práctica docente, no puede considerarse totalmente insignificante, sobre todo teniendo en cuenta que el proceso de asimilación por parte de un profesor o de una unidad (departamento) consume tiempo, energías y recursos. Cabe aclarar que se refiere al caso común del profesor con un cierto perfil académico en un área cualquiera (como, por ejemplo, un ingeniero topógrafo e hidráulico con especialidad en geomática, así como una base pedagógica que ha adquirido por experiencia, cursos, etc.).

Referente a los tiempos requeridos para asimilar el Modelo Educativo, podría valer la pena preguntarse: ¿Cuánto tiempo efectivo toma a un profesor capacitarse para poner en marcha el Modelo Educativo por competencias en sus cursos? Otra pregunta interesante es sobre el tiempo de calendario. El tiempo efectivo invertido, por ejemplo, podría ser el de unos 3 cursos de 20 horas, aunque espaciados a lo largo de 3 a 5 años del calendario escolar universitario. Como resultado de este tiempo dedicado al proceso de asimilación, se tiene un pequeño efecto adverso, pues este se llega a restar de los tiempos de clases. Además, en la curva de aprendizaje, los estudiantes y las clases que son de laboratorio de experimentación, de acuerdo a las leyes estadísticas, tendrán unos pocos o malos resultados.

En cuanto a los recursos materiales, estos son variables, pues dependen de los lugares, los capacitadores y las cuotas. Afortunadamente, la UG cuenta con su propio Departamento de Innovación Educativa, por lo que los recursos que se desvían del presupuesto docente para capacitación de los profesores se reducen considerablemente, así como los tiempos por desplazamiento a otros lugares. 


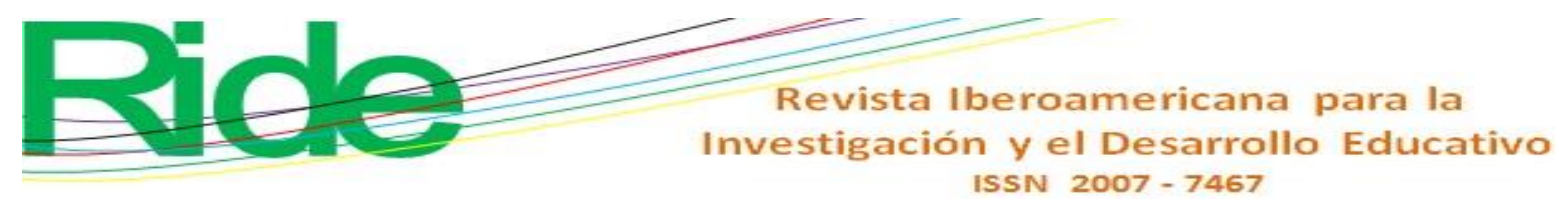

Ahora, ¿qué se puede decir del Modelo Educativo sobre la práctica docente a posteriori? Un primer paso es que el profesor universitario esté convencido de la pertinencia del Modelo Educativo. Por principio de cuentas, el Modelo Educativo ofrece una seguridad de actuación sobre el quehacer docente y sobre la repercusión que este pueda tener en la formación de estudiantes, ya que existe una coherencia rigurosa en él, producto de un estudio de fondo. Otra implicación del Modelo Educativo es un espacio de entendimiento común, en el que los diferentes actores del sistema comprenden y actúan sobre el mismo "lenguaje docente". Está claro que un espacio de entendimiento y un lenguaje docente, aunado al propósito trascendental que se persigue, crea una identidad tal como lo postula el Modelo Educativo. Asimismo, las características del Modelo Educativo son también un punto de partida y una guía para ejercicio de la creatividad docente.

Por consiguiente, el conocer mejor el Modelo Educativo de la UG permite reconocer los aspectos que la formación educacional tiene y puede mejorar para renovar la enseñanza en sus diferentes aspectos y, por consiguiente, innovar en la práctica docente (UG, 2011). La innovación en la práctica docente implica no solamente dar crédito a toda actividad que se desarrolla, sino también estimular al estudiante a la búsqueda de nueva información e indagar más allá de lo que se ve en clase sobre los temas tratados o a tratar.

El poder contar con una herramienta que permita desarrollar en el alumno su afán de búsqueda y de creatividad permite una mejor comprensión de los fenómenos, así como de las técnicas que se pueden utilizar para facilitar no solamente el aprendizaje, sino la práctica misma de los conocimientos. Y con ello tener la certeza de que en su vida profesional serán los mejores capacitados, ya que el intelecto, cuando este se fomenta, llega a ofrecer logros inimaginables en el transcurso universitario, así como de gran valía y de gran satisfacción como profesionales.

\section{Conclusiones}

Por lo anteriormente señalado, el Modelo Educativo de la UG es un referente que permite enmarcar la práctica docente. De manera que, bien aplicado, tendrá la virtud de garantizar la coherencia de las actividades formativas por parte de los estudiantes, así como de la práctica docente y administrativa de esta institución educativa. Asimismo, el Modelo Educativo crea un espacio y un lenguaje de entendimiento común donde los diferentes actores del sistema universitario pueden participar e interactuar más efectivamente. Es evidente que espacios y 


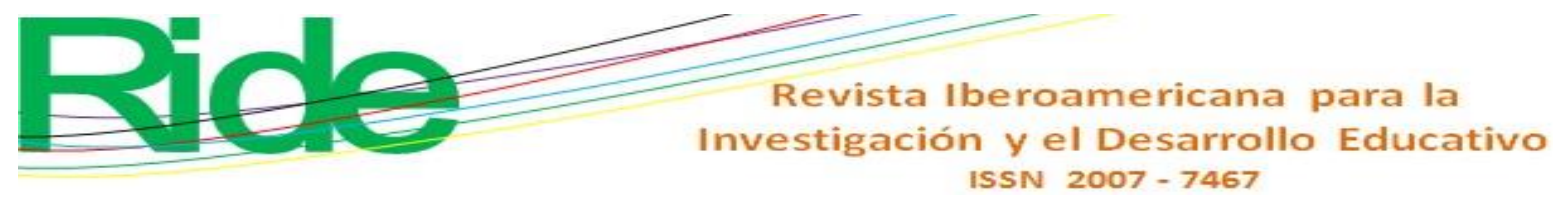

lenguaje común promueven el desarrollo de una identidad, así como una influencia benéfica hacia el logro de metas y persecución de ideales. Sin embargo, por sus características intrínsecas, se puede considerar al Modelo Educativo como un instrumento para el desarrollo creativo del quehacer universitario, tanto al interior como al exterior (su entorno social).

Asimismo, es pertinente mencionar que, a pesar de los obstáculos que se pueden presentar, el Modelo Educativo ofrece la alternativa para que la UG se consolide. Y puede ser incluso clave en el camino hacia una universidad con mejores cimientos y capaz de afrontar los retos del siglo XXI.

Por último, es fundamental señalar que en la presente investigación se llegó a las siguientes conclusiones finales:

1) Existe una clara coherencia entre los motivos y las estrategias pertenecientes a un mismo enfoque de aprendizaje. Asimismo, se observa una mayor consistencia en la escala de enfoque profundo.

2) Algunos estudiantes universitarios de las ingenierías con motivación profunda podrían hacer uso de estrategias superficiales si las demandas de la institución así lo requiriesen.

3) Los estudiantes de ingenierías con motivación superficial podrían llegar a utilizar estrategias profundas con la consiguiente ayuda por parte del profesor.

4) Es menester resaltar la importancia de diseñar, aplicar y evaluar programas de intervención, tanto para estudiantes como para profesores, capaces de modificar, en cada caso, los enfoques enseñanza-aprendizaje, ya que son los principales protagonistas de la acción educativa.

Finalmente, cabe mencionar que, con la presente investigación, se está contribuyendo a uno de los principales objetivos que se han ido estableciendo en el seno del Modelo Educativo de la UG: La calidad tanto de la enseñanza como del aprendizaje en el contexto de todas y cada una de las divisiones y campus de la Universidad de Guanajuato. 


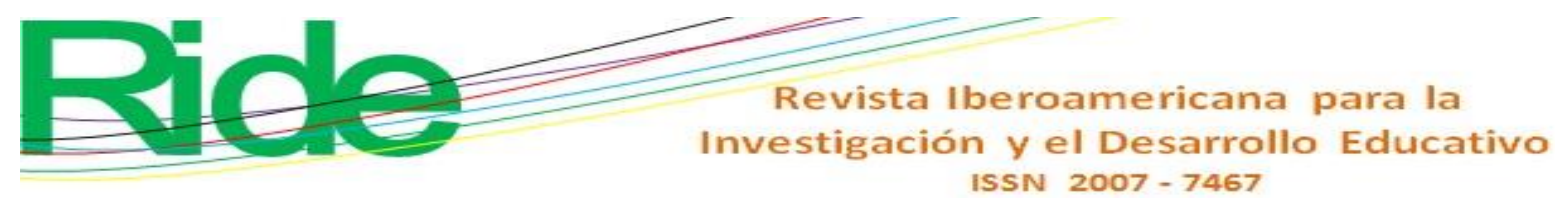

\section{Referencias}

Biggs, J. (2001). The revised two-factor Study Process Questionnaire: R-SPQ-2F. British Journal of Educational Psychology, (71), 133-149.

Flores, V. G. (2017). Evaluación del Modelo Educativo por Competencias Laborales en los Alumnos de la División de Ingenierías del Campus Guanajuato de la Universidad de Guanajuato. (tesis para optar por el grado de Doctorado en Pedagogía). Universidad Guanajuato, León.

Flores, V. G. y Alcalá, N. B. (2017). Evaluación del modelo educativo para la formación por competencias laborales en los alumnos de la división de ingenierías de la universidad de Guanajuato. Revista Electrónica sobre Tecnología, Educación y Sociedad, 1-19.

García, A. (2004). El proceso de enseñanza aprendizaje en la universidad: ¿Qué espera y cómo aprende el alumnado? Granada, España: Universidad de Granada.

Hernández, F., García, M., Martínez, P. Hervás, R. y Maquilón, J. (2002). Consistencia entre motivos y estrategias de aprendizaje en estudiantes universitarios. Revista de Investigación Educativa, 487-510.

Hernández, F., Martínez, P., Da Fonseca, P. y Rubio, M. (2005). Aprendizaje, competencias y rendimiento en educación superior. Madrid, España: La Muralla.

IBM. (2015). Manual de usuario SPSS 22. Estados Unidos: IBM Corporation.

Rueda, M. (2009). La evaluación del desempeño docente: consideraciones desde el enfoque por competencias. Revista Electrónica de Investigación Educativa, 1-16.

U. G. (17 de septiembre de 2018). Modelo Educativo de la Universidad de Guanajuato y sus Modelos Académicos. Obtenido de Universidad de Guanajuato: http://www.ugto.mx/images/pdf/modelo-educativo-y-sus-modelos-academicosuniversidad-de-guanajuato.pdf

Universidad de Deusto/Universidad de Groningen. (2007). Reflexiones y perspectivas de la Educación Superior en América Latina. Informe final: Proyecto Tuning-América Latina 2004-2007. España: Universidad de Deusto.

Universidad de Guanajuato [UG]. (2011). Modelo Académico. Recuperado de http://www.ingenierias.ugto.mx/secacad/ACADarchivos/ugMODELO-

\section{ACADEMICO.pdf.}




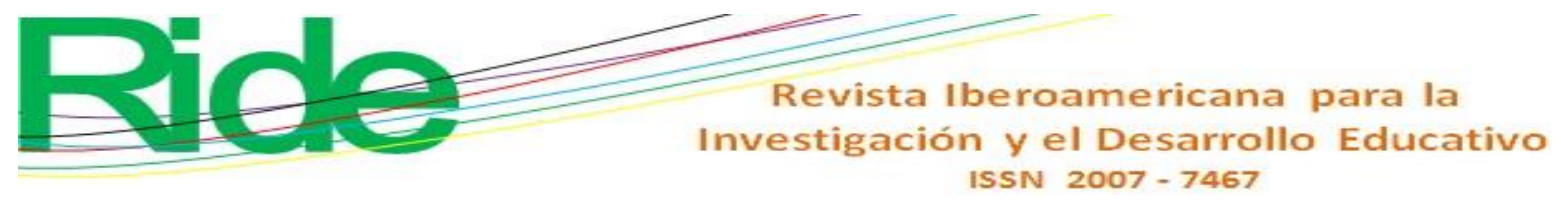

Universidad de Guanajuato [UG]. (15 de abril de 2018). Informe anual de actividades 2017. Recuperado de http://www.ugto.mx/informe2016-2017.

Universidad de Guanajuato [UG]. (15 de abril de 2018). Normatividad. Gaceta Universitaria. Recuperado de http://www.ugto.mx/gacetauniversitaria/images/normatividad/leyorganica-de-la-universidad-de-guanajuato-.pdf.

Universidad de Guanajuato [UG]. (15 de abril de 2018). Plan de Desarrollo Institucional. Gaceta Universitaria Recuperado de http://www.ugto.mx/gacetauniversitaria/images/normatividad/plan-de-desarrolloinstitucional.pdf.

Universidad de Guanajuato [UG]. (2018). Sistema de Información Integral Administrativa. Recuperado de http://www.daa.ugto.mx/SIIAEscolar.

XIV Congreso Nacional de Investigación Educativa. (2017). Memoria electrónica del XIV Congreso Nacional de Investigación Educativa 2017. Recuperado de http://comie.org.mx/congreso/memoriaelectronica/v14/index.htm. 
Revista Iberoamericana para la Investigación y el Desarrollo Educativo

ISSN $2007-7467$

\begin{tabular}{|c|c|c|c|}
\hline Rol de Contribución & \multicolumn{3}{|l|}{ Autor (es) } \\
\hline Conceptualización & $\begin{array}{l}\text { VICTOR GUILLERMO FLORES RODRÍGUEZ; } \\
\text { ALCALÁ CORTÉS (IGUAL) }\end{array}$ & NÉLIDA & BETHEL \\
\hline Metodología & VICTOR GUILLERMO FLORES RODRÍGUEZ & & \\
\hline Software & NO APLICA & & \\
\hline Validación & $\begin{array}{l}\text { VICTOR GUILLERMO FLORES RODRÍGUEZ; } \\
\text { ALCALÁ CORTÉS (QUE APOYA) }\end{array}$ & NÉLIDA & BETHEL \\
\hline Análisis Formal & VICTOR GUILLERMO FLORES RODRÍGUEZ & & \\
\hline Investigación & $\begin{array}{l}\text { VICTOR GUILLERMO FLORES RODRÍGUEZ; } \\
\text { ALCALÁ CORTÉS (QUE APOYA) }\end{array}$ & NÉLIDA & BETHEL \\
\hline Recursos & $\begin{array}{l}\text { VICTOR GUILLERMO FLORES RODRÍGUEZ; } \\
\text { ALCALÁ CORTÉS (QUE APOYA) }\end{array}$ & NÉLIDA & BETHEL \\
\hline Curación de datos & VICTOR GUILLERMO FLORES RODRÍGUEZ & & \\
\hline $\begin{array}{l}\text { Escritura - Preparación del borrador } \\
\text { original }\end{array}$ & $\begin{array}{l}\text { VICTOR GUILLERMO FLORES RODRÍGUEZ; } \\
\text { ALCALÁ CORTÉS (IGUAL) }\end{array}$ & NÉLIDA & BETHEL \\
\hline Escritura - Revisión y edición & $\begin{array}{l}\text { VICTOR GUILLERMO FLORES RODRÍGUEZ; } \\
\text { ALCALÁ CORTÉS (IGUAL) }\end{array}$ & NÉLIDA & BETHEL \\
\hline Visualización & $\begin{array}{l}\text { VICTOR GUILLERMO FLORES RODRÍGUEZ; } \\
\text { ALCALÁ CORTÉS (QUE APOYA) }\end{array}$ & NÉLIDA & BETHEL \\
\hline Supervisión & VICTOR GUILLERMO FLORES RODRÍGUEZ & & \\
\hline Administración de Proyectos & VICTOR GUILLERMO FLORES RODRÍGUEZ & & \\
\hline Adquisición de fondos & VICTOR GUILLERMO FLORES RODRÍGUEZ & & \\
\hline
\end{tabular}

